\title{
Pregnancy outcome in patients presented with peripartum cardiomyopathy: A five-year study in a tertiary care center
}

\author{
Sandip Sarkar ${ }^{1}$, Lipika Adhikari ${ }^{2}$ \\ ${ }^{1}$ Assistant Professor, Department of Gynaecology and Obstetrics, ${ }^{2}$ Associate Professor, Department of Cardiology, \\ R.G. Kar Medical College, Kolkata, West Bengal, India
}

Background: Peripartum cardiomyopathy (PPCM) is a relatively rare type of dilated cardiomyopathy that presents in late pregnancy or the early postpartum period. Although the condition is prevalent worldwide, women with black genealogy seem to have greater risk. Possible other risk factors are elderly maternal age, hypertension, multiparity, multifetal pregnancy, etc. Although the pathophysiology of PPCM is still obscure, recent studies suggest the important role of vasculo-hormonal pathway along with several other possible factors, for example., myocarditis, abnormal immune response to pregnancy, abnormal response to increased hemodynamic burden, malnutrition, inflammation, and apoptosis. Aims and Objectives: The aim of the objective is to find out the prevalence, risk factors, and pregnancy outcome of PPCM. Materials and Methods: Sixty-eight patients of PPCM admitted in G\&O department of R. G. KAR Medical college were taken. Clinical evaluations, Hematological evaluation, biochemical study, ECG, and Echocardiographywere done. Patient outcome was also compared between two groups of patients having Left Ventricular ejection fraction less than $35 \%$ and more than $35 \%$. Results: Prevalence of PPCM was $0.09 \%$, maternal mortality was $87 / 1000$ live births and perinatal mortality was $43 / 1000$ live births. Patients with lower ejection fraction showed poorer outcome. Conclusion: Patients with higher NYHA functional class, lower ejection fraction and larger left ventricular cavity showed worse maternal and perinatal outcome.

Key words: Chronic kidney disease; Coronary artery disease; Intrauterine growth restriction; Left ventricular ejection fraction; Left ventricular internal diameter in diastole; New York heart association; Peripartum cardiomyopathy; Pregnancy induced hypertension
Access this article online

Website:

http://nepjol.info/index.php/AJMS

DOI: $10.3126 / a j m s . v 13 i 3.42985$

E-ISSN: 2091-0576

P-ISSN: 2467-9100

Copyright (c) 2022 Asian Journal of Medical Sciences

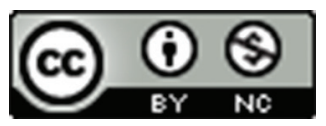

This work is licensed under a Creative Commons Attribution-NonCommercial 4.0 International License.

\section{INTRODUCTION}

The first large case series was published in New Orleans in 1937, but the syndrome remained poorly defined until the seminal publications by Pearson GD et al. US National Heart, Lung, and Blood Institute (NHLBI) in the late 1990s defined peripartum cardiomyopathy (PPCM) as heart failure that develops in the last month of pregnancy or up to 5 months postpartum with left ventricular systolic dysfunction (left ventricular ejection fraction (LVEF) $<45 \%$ or fractional shortening $<30 \%$, or both) ${ }^{1,2}$ Exclusion of women with heart failure before the final month of pregnancy was to exclude pre-existing cardiomyopathies. But patients who meet the criteria for PPCM before 36 weeks of gestation, 3-6 raising concerns that the NHLBI definition may lead to under diagnosis of PPCM. Hence 2010 the European Society of Cardiology redefined PPCM as follows. Diagnostic criteria for PPCM includes 1) Development of heart failure in last trimester of pregnancy or within months of delivery 2) The absence of determinable etiology of heart failure 3) The absence of demonstrable heart disease before last trimester of pregnancy and 4) Left ventricular systolic dysfunction demonstrated by echocardiography with LVEF $<45 \%$, fractional shortening $<30 \%$ or both. Diagnosis of PPCM is challenging in the last month of pregnancy as normal pregnant women experience dyspnoea fatigue and pedal edema. Several hypotheses such as dysregulated 
secretion of prolactin by the anterior pituitary gland, upregulation of endothelial microRNA-146a (miRNA146a), and placental secretion of soluble fms-like tyrosine kinase receptor 1 (sFlt-1) may result endothelial dysfunction and cardiomyocyte death. Risk factors of PPCM are many, natural history of the disease is also varied and exact risk of recurrence is also unknown. Treatment of PPCM is just like other forms of systolic heart failure, i.e., maintaining volume status, addressing maladaptive neurohormonal response, and early detection along with treatment of thromboembolic and arrhythmic complications. Intravenous immunoglobulin, pentoxifyllin, and levosimendan were tried in different randomized, controlled trials but did not show statistically significant beneficial effect. Inhibition of pituitary prolactin secretion with, an ergot alkaloid and dopamine D2-receptor agonist, showed to have favorable neurohormonal and hemodynamic effects in patients with heart failure. But adverse maternal vascular events and potential harm to the newborn by suppression of lactation must be considered. In nutshell the use of bromocriptine in PPCM remains investigational. Although there are great advances in the understanding of the definition, etiology, risk factors, and treatment of PPCM since its inception, many unanswered questions still remain. The purposes of this study are to describe the clinical profile, natural history, maternal-fetal outcome, and response to treatment of the enrolled patients.

\section{Aims and objectives}

The present study was undertaken to explore the prevalence, risk factors, complications, and outcome of PPCM.

\section{MATERIALS AND METHODS}

A total of sixty-eight patients admitted in the gynecology department of R. G. Kar Medical college for a period of 5 years from October 2016 to November 2021 were included in the study. Informed consent of patients, enrolled in the study was taken. Patients who came to the hospital with clinical feature of heart failure and fulfil the criteria of PPCM were included in the study.

\section{Inclusion criteria}

Patients who came in the last trimester of pregnancy with clinical feature of heart failure i.e. dyspnoea, orthopnea, cough, generalized swelling of body, palpitation, syncope were immediately evaluated for NYHA functional class and staging. Routine investigations e.g. $\mathrm{Hb} \%$, $\mathrm{PPBS}$, TSH, Serology, fetal ultrasound, Echocardiography were done. After echocardiographic evaluation who met the criteria for PPCM were included in the study. Comparative analysis was performed between two subgroups of PPCM i.e. LVEF $<35 \%$ and LVEF $>35 \%$. Medical treatment was started and counseled for regular follow-up.

\section{Exclusion criteria}

1) Patients with congenital heart disease, valvular heart disease, coronary artery disease, hypertensive heart disease, Diabetes mellitus, and chronic kidney disease were excluded from the study.

2) Patients who already had a history of dilated, restrictive, or hypertrophic cardiomyopathy were excluded. But patients who already had a history of PPCM and conceived for $2^{\text {nd }}$ or $3^{\text {rd }}$ time were included in the study.

3) Patients who were positive for RT PCR COVID were excluded from the study.

\section{RESULTS}

A total of around 76000 delivery occurred in the R. G. KAR Medical college during the study period and the number of PPCM was sixty-eight. The prevalence of the disease was $0.09 \%$. Forty-one patients presented in the first post-partum month, twenty patients came in the last month of pregnancy and seven patients came after the first postpartum month. Although most of the patients were between 25 and 30 years of age eighteen patients were between 18 and 25 years of age. Multifoetal pregnancy was seen in seven patients with PPCM and multiparity was seen in thirty-four patients (Table 1).

Most of the patients presented with clinical features of heart failure, 18 patients presented with arrhythmia (Ventricular tachycardia $=10$, Atrial fibrillation $=08$ ) and 09 patients came with cerebrovascular accident. Out of 68 patients 21 patients came out with complete recovery of cardiac function, 17 patients showed similar status of cardiac function and 30 patients had deterioration of cardiac function. Six patients expired in hospital who were multipara and had severe Left ventricular systolic dysfunction (Table 2).

Maternal mortality was 87 per thousand live birth and it was due to heart failure not responding to conventional anti failure medical therapy(diuretic, digoxine, nitratehydralazine, and anticoagulant antiarrhythmic drugs as and when required). Intrauterine growth retardation babies were 24 in number, premature birth in 30, and still birth in 06. Mode of delivery was assisted vaginal delivery in 44 and cesarean section in 24. Proportion of patients with LVEF $<35 \%$ were more likely to have arrhythmia and death than those with LVEF $>35 \%$ (Table 3).

Cardiac complications like arrhythmia, embolic manifestations, and death were more in patients with $\mathrm{LVEF}<35 \%$ but it was not statistically significant. Patients with $\mathrm{LVEF}<35 \%$ had higher maternal and perinatal mortality rate. LV systolic function improved significantly 


\begin{tabular}{|c|c|c|}
\hline & Number & Percentage \\
\hline \multicolumn{3}{|l|}{ Clinical detection } \\
\hline Last month of pregnancy & 20 & 30 \\
\hline $1^{\text {st }}$ post partum month & 41 & 60 \\
\hline$>1$ month post partum & 07 & 10 \\
\hline \multicolumn{3}{|l|}{ Age at presentation } \\
\hline$<25$ years & 18 & 27 \\
\hline $25-30$ years & 41 & 60 \\
\hline$>30$ years & 09 & 13 \\
\hline \multicolumn{3}{|l|}{$\mathrm{PIH}$} \\
\hline Yes & 17 & 25 \\
\hline No & 51 & 75 \\
\hline \multicolumn{3}{|l|}{ Multiparity } \\
\hline Yes & 34 & 50 \\
\hline No & 34 & 50 \\
\hline \multicolumn{3}{|l|}{ Multifetus } \\
\hline Yes & 07 & 09 \\
\hline No & 61 & 91 \\
\hline
\end{tabular}

\begin{tabular}{|c|c|c|c|}
\hline & $\begin{array}{c}\text { No of } \\
\text { patients with } \\
\text { LVEF }<35 \%\end{array}$ & $\begin{array}{c}\text { No of } \\
\text { patients with } \\
\text { LVEF>35\% }\end{array}$ & $\begin{array}{l}\text { Fishers } \\
\text { exact } \\
\text { P value } \\
\end{array}$ \\
\hline NYHA III/IV & 48 & 20 & $<0.05$ \\
\hline Arrhythmia & 15 & 03 & $<0.05$ \\
\hline Emboli & 06 & 03 & 0.684 \\
\hline Death & 04 & 02 & 0.474 \\
\hline
\end{tabular}

in patients with LVEF $>35 \%$ (P value 0.0145) as compared with patients with LVEF $<35 \%$ who showed deterioration of systolic function or status-quo. Adverse foetal outcome like IUGR premature delivery or perinatal mortality were more in patients with more compromised systolic function though not statistically significant.

\section{DISCUSSION}

In the USA, its incidence is between one in 900 and one in 4000 live births. In a recent study, its incidence increased from one in 1181 live births in 2004 to one in 849 live births in 2011. ${ }^{3}$ Rising maternal age and multiple gestation due to IVF may be the risk factors for PPCM. If we see the global incidence of PPCM, its incidence is highest in Nigeria (one in 100 live births) ${ }^{4}$ and Haiti (one in 300 live births $)^{5}$ Possible reasons for this include genetic predisposition, a high prevalence of selenium deficiency ${ }^{6}$, and a high prevalence of zinc deficiency. ${ }^{7}$ Black women have an increased risk of PPCM. ${ }^{8}$ In our study prevalence of PPCM was 0.95 per thousand live births and possible explanation is reception of complicated cases as referral centres. Maternal age of 30 years or more is independent risk factor for PPCM, compared with women $<30$ years. ${ }^{9}$ In

\begin{tabular}{lccc}
\multicolumn{4}{c}{ Table 3: Pregnancy outcome in PPCM } \\
\hline $\begin{array}{c}\text { No of } \\
\text { patients with } \\
\text { LVEF<35\% }\end{array}$ & $\begin{array}{c}\text { No of } \\
\text { patients with } \\
\text { LVEF }>\mathbf{3 5 \%}\end{array}$ & $\begin{array}{c}\text { Fishers } \\
\text { exact } \\
\text { P value }\end{array}$ \\
\hline $\begin{array}{l}\text { Maternal mortality } \\
\begin{array}{l}\text { Perinatal mortality } \\
\text { LV function }\end{array}\end{array}$ & 04 & 02 & 0.316 \\
improves & 04 & 02 & 0.316 \\
LV function & 06 & 15 & 0.01 \\
$\begin{array}{l}\text { deteriorates } \\
\text { IUGR }\end{array}$ & 24 & 06 & 0.01 \\
Premature & 18 & 06 & 0.05 \\
\hline PPCM: Peripartum cardiomyopathy & 09 & 1.0 \\
\hline
\end{tabular}

our observation, most of the patients with PPCM were in 25-30 years of age group $(n=41)$. A 2013 meta-analysis of 22 studies found a $22 \%$ prevalence of pre-eclampsia among women with PPCM, more than 4 times the estimated global prevalence. ${ }^{10}$ In our study, PIH was seen in 17 patients $(25 \%)$ of PPCM which is quite high as compared to incidence of PIH in overall population. Similar rates of $\mathrm{LV}$ recovery were observed in patients with and without a history of PIH and so the later does not seem to be a cause of LV dysfunction. ${ }^{11}$ Most studies in the United States showed the development of PPCM in conjunction with first and second pregnancy in $>50 \%$. In our study, $50 \%$ of patients were multipara and 04 patients presented in their fourth pregnancy. Though multiparity was established to be a risk factor for PPCM our data did not support a strong association. Patients with LVEF $<35 \%$ came with NYHA functional class III/IV but 20 patients with LVEF $>35 \%$ also presented with severe dyspnoea and orthopnoea. Arrhythmia was more in severely compromised LV and 06 deaths were due to intractable heart failure. Thrombo embolic manifestation was seen in $06(9 \%)$ patients and this percentage was more in PPCM patients as compared with dilated cardiomyopathy. Amos et al., in their study, found similar result. ${ }^{12}$ Recovery of LV function $(>20 \%$ of baseline) within 12 months of delivery was seen in 21 patients and it is more in patients with left ventricular internal diameter in diastole $<55 \mathrm{~mm}$ and LVEF $>35 \%$ $(\mathrm{P}<0.05)$. Reports from Utah PPCM registry described LV recovery in $62 \%$ of 58 patients with an average time of 9 months. ${ }^{13}$ Modi et al., reported recovery of LV function in only $35 \%$ of 40 indigent patients with a median time to recovery of 54 months and this poor outcome is possibly due to African American ethnicity. ${ }^{14}$ IUGR and prematurity were more in patients with severe LV systolic dysfunction. As assisted vaginal delivery prevents the potential risk of anesthesia and surgical delivery, the vaginal route is always preferred. ${ }^{15}$ In our study also cesarean delivery was only for fetal distress and obstructed labor. Patients should be advised on the risk of subsequent pregnancy and encouraged to adopt a safe and effective contraceptive method. ${ }^{16}$ 
Limitations of the study

We failed to follow up all patients for prolonged period because they did not turn up in OPD and we did not had the facility for door to door survey. We failed to do speckle tracking in our echodoppler machine due to nonavailability.

\section{CONCLUSION}

Patients presented with higher NYHA functional class, lower ejection fraction and higher LVIDD showed worse maternal and perinatal outcome along with poorer recovery of LV function.

\section{ACKNOWLEDGMENTS}

We are grateful to the Principal, Dean and Medical Superintendent of R. G. Kar Medical College for allowing us to conduct the study. We are also thankful to all the staff of department of Cardiology and Gynaecology and Obstetrics for co-operating with us to carry out the study. Finally, we are very much grateful to all the participants of this study for their full hearted support and co-operations.

\section{REFERENCES}

1. Pearson GD, Veille JC, Rahimtoola S, Hsia J, Oakley CM, Hosenpud JD, et al. Peripartum cardiomyopathy: National heart, lung, and blood institute and office of rare diseases (national institutes of health) workshop recommendations and review. JAMA. 2000;283(9):1183-1188.

https://doi.org/10.1001/jama.283.9.1183

2. Hibbard JU, Lindheimer M and Lang RM. A modified definition for peripartum cardiomyopathy and prognosis based on echocardiography. Obstet Gynecol. 1999;94(2):311-316. https://doi.org/10.1016/s0029-7844(99)00293-8

3. Kolte D, Khera S, Aronow WS, Palaniswamy C, Mujib M, Ahn C, et al. Temporal trends in incidence and outcomes of peripartum cardiomyopathy in the United States: A nationwide populationbased study. J Am Heart Assoc. 2014;3(3):e001056.

https://doi.org/10.1161/JAHA.114.001056

4. Arany $Z$ and Elkayam U. Peripartum cardiomyopathy. Circulation. 2016;133(14):1397-1409.

https://doi.org/10.1161/CIRCULATIONAHA.115.020491
5. Isezuo SA and Abubakar SA. Epidemiologic profile of peripartum cardiomyopathy in a tertiary care hospital. Ethn Dis. 2007; 17(2):228-233

6. Karaye KM, Yahaya IA, Lindmark K and Henein MY. Serum selenium and ceruloplasmin in Nigerians with peripartum cardiomyopathy. Int J Mol Sci. 2015;16(4):7644-54. https://doi.org/10.3390/ijms16047644

7. Fett JD. Peripartum cardiomyopathy: A puzzle closer to solution. World J Cardiol. 2014;6(3):87-99. https://doi.org/10.4330/wjc.v6.i3.87

8. Elkayam U. Clinical characteristics of peripartum cardiomyopathy in the United States: Diagnosis, prognosis, and management. J Am Coll Cardiol. 2011;58(7):659-670. https://doi.org/10.1016/j.jacc.2011.03.047

9. Kao DP, Hsich E and Lindenfeld J. Characteristics, adverse events, and racial differences among delivering mothers with peripartum cardiomyopathy. JACC Heart Fail. 2013;1(5):409-416. https://doi.org/10.1016/j.jchf.2013.04.011

10. Bello N, Rendon IS and Arany Z. The relationship between preeclampsia and peripartum cardiomyopathy: A systematic review and meta-analysis. J Am Coll Cardiol. 2013;62(18):1715-1723. https://doi.org/10.1016/j. jacc.2013.08.717

11. Krishnamoorthy P, Garg J, Palaniswamy C, Pandey A, Ahmad H, Frishman $\mathrm{WH}$, et al. Epidemiology and outcomes of peripartum cardiomyopathy in the United States: Findings from the nationwide inpatient sample. J Cardiovasc Med (Hagerstown). 2016;17:756-7561.

https://doi.org/10.2459/JCM.0000000000000222

12. Amos A, Jaber WA and Russel SD. Improved outcomes in peripartum cardiomyopathy with contemporary. Am Heart J. 2006;152(3):509-513.

https://doi.org/10.1016/j.ahj.2006.02.008

13. Rasmusson K, Budge D, Alharethi R, Brunisholz K, Connolly J, Jensen $\mathrm{K}$, et al. Long term outcome in patients with peripartum cardiomyopathy and no recovery of left ventricular function. J Card Fail. 2010;16:S97.

14. Modi KA, Illum S, Jariatui K, Caldito G and Reddy PC. Poor outcome of indigent patients with peripartum cardiomyopathy in the United States. Am J Obstet Gynecol. 2009;201(2):171.e1-171.e5. https://doi.org/10.1016/j.ajog.2009.04.037

15. Ecker JL and Frigoletto FD Jr., Cesarean delivery and the risk benefit calculus. N Engl J Med. 2007;201:171.e1-171.e5.

16. Thorne S, MacGregor A and Nelson-Piercy C. Risks of contraception and pregnancy in heart disease. Heart. 2006;92(10):1520-1525.

https://doi.org/10.1136/hrt.2006.095240

\footnotetext{
Authors Contribution:

SS- Concept, design, preparation of first draft, Statistical analysis and interpretation, Interpretation of results, manuscript preparation and revision of the manuscript; LA- Concept, manuscript preparation and revision of the manuscript, review of the literature and coordination, Collection of data, preparation of first draft, review of the literature

Work attributed to:

Department of Gynaecology and Obstetrics, R. G. Kar Medical College, Kolkata - 700 004, West Bengal, India

Orcid ID:

Dr. Sandip Sarkar - (1) https://orcid.org/0000-0002-0621-024X

Dr. Lipika Adhikari - (1) https://orcid.org/0000-0002-3927-5197

Source of Support: Nil, Conflict of Interest: None declared.
} 